\title{
Dietary trigger factors of migraine and tension- type headache in a South East Asian country
}

This article was published in the following Dove Press journal: Journal of Pain Research

\author{
Mei-Ling Sharon Tai' \\ Jun Fai Yap' \\ Cheng Beh Goh ${ }^{1,2}$ \\ 'Division of Neurology, Department \\ of Medicine, Faculty of Medicine, \\ University of Malaya, Kuala Lumpur, \\ Malaysia; ${ }^{2}$ Department of Medicine, \\ Sultan Ismail Hospital, Johor Bahru, \\ Johor, Malaysia
}

Background: The literature on the dietary trigger factors of headache among the South East Asians is limited.

Objective: The objective of the study was to examine the dietary trigger factors of migraine and tension-type headache (TTH) in Malaysian patients, consisting of Malays, Chinese and Indians. Methods: In this prospective cross-sectional study, patients presenting with migraine and TTH to a neurology clinic between April 2010 and June 2017 were recruited. The patients were given a comprehensive dietary list consisting of 25 specified types of food and drink items as well as other unspecified types of food and drink items which were possible dietary triggers. The data on these dietary triggers and missing meals were collected.

Results: A total of 684 patients with headache (319 migraine and $365 \mathrm{TTH}$ patients) were recruited. One hundred and fifty-eight $(23.1 \%)$ patients had missing meals as trigger. Two hundred and fifty-five (37.3\%) patients had dietary triggers; 141 (44.2\%) patients with migraine and $114(31.2 \%)$ patients with TTH had dietary triggers. Eighty-four (52.8\%) Malay, 28 (41.8\%) Chinese, 25 (32.5\%) Indian migraine patients and five (38.5\%) migraine patients from other ethnic groups, had dietary triggers. Some 58 (40.0\%) Malay, 27 (25.2\%) Chinese, 22 (23.9\%) Indian patients and 7 (29.2\%) patients from other ethnic groups with TTH had dietary triggers. The most common dietary trigger factors were coffee (19.9\%), chocolate (7.5\%) and food rich in monosodium glutamate (5.6\%). Logistic regression showed that chocolate (OR 2.16, 95\% CI 1.06-4.41, $p=0.035$ ) and coffee (OR $1.73,95 \%$ CI 1.12-2.68, $p=0.014$ ) were significantly associated with migraine compared to TTH.

Conclusion: Chocolate and coffee significantly triggered migraine compared to TTH. Interethnic differences were observed for dietary trigger factors.

Keywords: headache, food, dietary, trigger, factors, migraine, tension-type headache

\section{Introduction}

Headache is one of the most common diseases in the world. ${ }^{1}$ The two most common primary headache subtypes in the world are tension-type headache (TTH) and migraine. ${ }^{2}$ In Malaysia, headache is a common presenting complaint to general practitioners and outpatients' clinics. ${ }^{3}$ In a previous community study in Malaysia, 1-year prevalence for headache was $26.5 \%$ for tension-type headache, and $9.0 \%$ for migraine. ${ }^{3}$

The primary headaches, especially migraine, can lead to significant disabilities. ${ }^{2}$ Untreated or poorly managed headaches result in reduction of work productivity and economic consequences. ${ }^{4}$ An assessment of the trigger factors of headache will be beneficial and important in the management of headache. ${ }^{5}$ Moreover, the headaches
Correspondence: Mei-Ling Sharon Tai Division of Neurology, Department of Medicine, Faculty of Medicine, University of Malaya, 50603 Lembah Pantai, Kuala Lumpur, Malaysia

Tel +603 79492868

Email sharont1990@gmail.com 
which are presented to the secondary or tertiary care clinics are burdensome to the patients. ${ }^{5}$ The frequent headaches and especially the disabling headaches, may make the trigger factors more obvious to the patients. ${ }^{6}$

Dietary factors, alcohol and missing meals are the more common trigger factors of migraine and TTH. ${ }^{7,8}$ The percentages of some of the dietary factors provoking TTH and migraine headaches can be different. ${ }^{8}$ The role of dietary factors in precipitating migraine episodes is of increasing interest. ${ }^{9,10}$ This is because the clinical expression of migraine is significantly impacted by dietary issues. ${ }^{11}$ The classical dietary trigger factors of migraine are known to be chocolate, cheese and coffee. ${ }^{7,8,12-16}$ When the offending foods are avoided, the headache improves. ${ }^{17}$

Malaysia is a developing country in South East Asia. This country is near the equator and has tropical climate. Malaysia consists of three major ethnic groups (Malays, Chinese and Indians) with various unique cultures. This multi-ethnic population can be considered to be representative of the Asian population. Moreover, the literature on the dietary trigger factors among the South East Asians, and especially Malays, is scarce. It is important to know the triggers among the Malays because they can avoid these foods and thus this will improve the frequency of headaches.

We hypothesized that the Malay patients had different dietary triggers compared to the Chinese and Indians. We also hypothesized that a disease model and an illness model could possible explain the differences in dietary triggers between the three ethnic groups.

The objective of the study was to examine the dietary trigger factors of migraine and TTH in the Malaysian patients, consisting of Malays, Chinese and Indians.

\section{Methodology} Patient selection

The study was a prospective cross-sectional study conducted at the University Malaya Medical Centre, Kuala Lumpur, Malaysia. The period of study was between April 2010 and June 2017. Consecutive patients, aged at least 18 years old were recruited from the neurology outpatient clinic. The patients who were referred to the neurology clinic for TTH and migraine were included in the study. They presented with headache at least once monthly for at least 3 months.

The patients with trigeminal neuralgia, glossopharyngeal neuralgia, cluster headache, headache secondary to intracranial mass lesions and other secondary headaches, were excluded. Informed written consent was obtained from all the study participants or their legally acceptable representatives.
Ethics approval and consent to participate was obtained, and the study was approved, by the institutional ethics committee of University Malaya Medical Centre.

\section{Study design and data collection}

A structured headache questionnaire was used for the study. The classification of the headache subtypes of the first group of patients recruited between 2010 and 2013 before the publication of International Headache Criteria III (ICHD-III) beta criteria, was made according to the ICHD-II classification. ${ }^{18}$ We subsequently re-evaluated the headache subtype classification based on the ICHD-III beta criteria, to ensure that the ICHD-III beta criteria were fulfilled. ${ }^{19}$ The second group of patients were recruited after the ICHD-III beta criteria were published in 2013, and the classification was based on the ICHD-III beta criteria. ${ }^{19}$

The data about the demographic characteristics, such as age, gender and ethnic group, as well as weight and height were recorded. Body mass index (BMI) was calculated based on the weight and height. The data on the headache characteristics included frequency, site, character and intensity were also collected.

The patients were given a comprehensive dietary check list in the neurology clinic. In the dietary check list, the patients were asked to identify the dietary triggers. The patients were informed to circle either "yes" or "no" in the dietary list. If any of the food or drink item triggered headache, the patient would circle "yes." If the food or drink item did not trigger headache, the patient would circle "no." Each suspected dietary trigger resulted in migraine or TTH episode. Each migraine or TTH episode was preceded by the dietary trigger.

The dietary list included: chocolate, coffee, cheese, food rich in monosodium glutamate (MSG), mutton, "heaty" food, fatty meal, fried food, durian, tea, soft drinks, spicy food, beef, oranges, instant noodles, onions, pineapples, lime, eggs, tomatoes, nuts, banana, sugarcane, mango and alcohol (25 various types of food and drink items), as well as "other types of food and drink items." We have taken into account and included the typical Malaysian multi-racial diet. The patients recorded the food they ate which triggered headache, in the list of dietary items. We also collected the data on missing meals.

\section{Case definitions}

The diagnosis of various subtypes of headache was based on the International Headache Society (IHS) Criteria (ICHD-III). ${ }^{19}$ The subtypes of headache were: migraine 
with aura, migraine without aura, infrequent episodic TTH, frequent episodic TTH and chronic TTH. Chronic daily headache was defined as a headache frequency $\geq 15$ days in 1 month, with duration of $>4$ hours in 1 day. ${ }^{20}$

"Heaty" food is based on ancient Chinese concepts and indigenous culture. "Heaty" food is commonly used as a form of expressing symptoms often associated with emotional or physical reactions such as irritability, short temper, fever, flushing of face, dark yellow urine, nose bleed, acne eruption, rashes, mouth ulcers and indigestion..$^{20}$ "Heaty" food includes pepper, ginger, soybean oil, coriander (Chinese parsley), dates, dill seed, and garlic. ${ }^{20}$

\section{Statistical analysis}

All descriptive statistics were done using Statistical Package for Social Sciences, SPSS (Version 21.0, SPSS Inc., Chicago, IL, USA). For categorical data, Chi-square test or Fisher's test were used. Continuous variables were expressed as means and analyzed with Student's $t$-test. Binary logistic regression analysis was performed to compare the various dietary triggers with migraine and TTH. A $p$ value of $<0.05$ was taken as statistically significant.

\section{Results}

A total of 715 patients met the inclusion criteria of migraine and TTH. However, 21 patients were excluded due to incomplete dietary data. Therefore, we recruited and evaluated the dietary triggers of 684 patients with migraine and TTH.

\section{Basic demography characteristics}

Table 1 shows the demographic characteristics of the study population.

Table I Demographic characteristics of study patients

\begin{tabular}{|c|c|c|c|c|}
\hline $\begin{array}{l}\text { Baseline } \\
\text { characteristics }\end{array}$ & $\begin{array}{l}\text { All patients } \\
(n=684)\end{array}$ & $\begin{array}{l}\text { Migraine } \\
(n=3 \mid 9)\end{array}$ & $\begin{array}{l}\text { TTH } \\
(n=365)\end{array}$ & $p$-value \\
\hline Age $($ mean $\pm S D)$ & $42.1 \pm 17.1$ & $37.1 \pm 14.3$ & $46.5 \pm 18.1$ & $<0.0001$ \\
\hline \multicolumn{5}{|l|}{ Gender (n, \%) } \\
\hline Male & $163(24)$ & $58(18.2)$ & $105(28.8)$ & 0.001 \\
\hline Female & $521(76)$ & $26 \mid(8 I .8)$ & 260 (7I.2) & \\
\hline \multicolumn{5}{|l|}{$\begin{array}{l}\text { Ethnic groups } \\
(\mathrm{n}, \%)\end{array}$} \\
\hline Malay & $304(44.4)$ & 159 (49.8) & 145 (39.7) & 0.009 \\
\hline Chinese & $174(25.4)$ & $69(21.6)$ & $105(28.8)$ & 0.035 \\
\hline Indian & $169(24.7)$ & $78(24.5)$ & 91 (24.9) & 0.93 \\
\hline Others & $37(5.4)$ & $13(4.1)$ & $24(6.6)$ & 0.18 \\
\hline $\begin{array}{l}\text { BMI }\left(\mathrm{kg} / \mathrm{m}^{2}\right) \\
(\mathrm{mean} \pm \mathrm{SD})\end{array}$ & $24.60 \pm 5.12$ & $25.07 \pm 5.51$ & $24.18 \pm 4.71$ & 0.023 \\
\hline
\end{tabular}

Note: $p$-value $<0.05$ was considered statistically significant (shown in bold).

Abbreviations: TTH, tension-type headache; BMI, body mass index.

\section{Types of headache according to ICHD-III classification}

A total of 319 (46.6\%) patients had migraine, whereas 365 (53.4\%) patients had TTH. The most common subtype of headache was frequent TTH (212 patients, 31.0\%). The other subtypes were migraine without aura (188 patients, $27.5 \%$ ), migraine with aura (128 patients, $18.7 \%$ ), chronic TTH (106 patients, 15.5\%) and infrequent TTH (50 patients, $7.3 \%)$. Some $91(28.8 \%)$ patients had chronic migraine.

\section{Trigger factors for the headache}

Altogether, 255 (37.3\%) patients had dietary trigger factors; 141 (44.2\%) patients with migraine and 114 (31.2\%) patients with TTH had dietary triggers. A total of 158 (23.1\%) patients had missing meal as trigger; $98(30.7 \%)$ patients with migraine and $60(16.4 \%)$ patients with TTH had missing meals.

The univariate analysis showed that missing meals $(p<0.0001)$ and dietary trigger factors $(p<0.0001)$ were significantly more common in the patients with migraine compared to TTH (Table 2).

\section{Dietary trigger factors}

There were "yes" responses for the 25 dietary triggers in the check list. No patient circled "yes" for the "other types of food and drink items." The most common dietary trigger factors were coffee (136 patients, 19.9\%), followed by chocolate (51 patients, 7.5\%) and food rich in MSG (38 patients, $5.6 \%)$. Univariate analysis showed that chocolate $(p<0.0001)$, coffee $(p=0.001)$, food rich in MSG $(p=0.007)$, soft drinks $(p=0.019)$, and instant noodles $(p=0.022)$ were significantly more common in the patients with migraine compared to TTH (Table 3).

Logistic regression showed that chocolate (OR 2.16, 95\% CI 1.06-4.41, $p=0.035$ ) and coffee (OR 1.73, 95\% CI 1.12-2.68, $p=0.014)$ were significantly associated with migraine compared to TTH (Table 4).

Table 2 Frequency of dietary trigger and missing meals in the patients with migraine and TTH

\begin{tabular}{lllll}
\hline $\begin{array}{l}\text { Trigger } \\
\text { factors }\end{array}$ & $\begin{array}{l}\text { All patients } \\
(\mathbf{n}=\mathbf{6 8 4})\end{array}$ & $\begin{array}{l}\text { Migraine } \\
(\mathbf{n}=\mathbf{3 1 9})\end{array}$ & $\begin{array}{l}\text { TTH } \\
(\mathbf{n}=\mathbf{3 6 5})\end{array}$ & -value \\
\hline Dietary & $255(37.3 \%)$ & $14 \mathrm{I}(44.2 \%)$ & $114(31.2 \%)$ & $<0.000 \mathrm{I}$ \\
Missing meals & $158(23.1 \%)$ & $98(30.7 \%)$ & $60(16.4 \%)$ & $<0.000 \mathrm{I}$ \\
\hline
\end{tabular}

Abbreviation: TTH, tension-type headache. 
Table 3 Frequency of various types of dietary trigger factors in the patients with migraine and TTH

\begin{tabular}{|c|c|c|c|c|}
\hline Trigger factors & $\begin{array}{l}\text { All patients } \\
(n=684)\end{array}$ & $\begin{array}{l}\text { Migraine } \\
(n=3 \mid 9)\end{array}$ & $\begin{array}{l}\text { TTH } \\
(n=365)\end{array}$ & $p$-value \\
\hline Chocolate & $5 \mathrm{I}(7.5 \%)$ & 37 (I I.6\%) & $14(3.8 \%)$ & $<0.0001$ \\
\hline Coffee & 136 (19.9\%) & $8 \mathrm{I}(25.4 \%)$ & 55 (15.1\%) & 0.001 \\
\hline Food rich in MSG & $38(5.6 \%)$ & 26 (8.2\%) & 12 (3.3\%) & 0.007 \\
\hline “Heaty" food & 37 (5.4\%) & $20(6.3 \%)$ & 17 (4.7\%) & 0.40 \\
\hline Mutton & $36(5.3 \%)$ & $20(6.3 \%)$ & $16(4.4 \%)$ & 0.31 \\
\hline Fatty meal & 29 (4.2\%) & $13(4.1 \%)$ & $16(4.4 \%)$ & 0.85 \\
\hline Fried food & $29(4.2 \%)$ & $12(3.8 \%)$ & 17 (4.7\%) & 0.58 \\
\hline Durian & 27 (3.9\%) & 14 (4.4\%) & $13(3.6 \%)$ & 0.70 \\
\hline Tea & 25 (3.7\%) & 15 (4.7\%) & 10 (2.7\%) & 0.22 \\
\hline Soft drinks & $19(2.8 \%)$ & 14 (4.4\%) & $5(1.4 \%)$ & 0.019 \\
\hline Cheese & $18(2.6 \%)$ & $12(3.8 \%)$ & $6(1.6 \%)$ & 0.097 \\
\hline Alcohol & $14(2.0 \%)$ & $8(2.5 \%)$ & $6(1.6 \%)$ & 0.59 \\
\hline Spicy food & I 4 (2.0\%) & 9 (2.8\%) & 5 (1.4\%) & 0.28 \\
\hline Beef & 13 (1.9\%) & 7 (2.2\%) & $6(1.6 \%)$ & 0.78 \\
\hline Oranges & $9(1.3 \%)$ & $6(1.9 \%)$ & $3(0.8 \%)$ & 0.32 \\
\hline Instant noodles & $5(0.7 \%)$ & $5(1.6 \%)$ & $0(0 \%)$ & 0.022 \\
\hline Onions & $4(0.6 \%)$ & $3(0.9 \%)$ & I $(0.3 \%)$ & 0.34 \\
\hline Pineapples & $4(0.6 \%)$ & I (0.3\%) & $3(0.8 \%)$ & 0.63 \\
\hline Lime & $3(0.4 \%)$ & I (0.3\%) & $2(0.5 \%)$ & 1.00 \\
\hline Egg & $3(0.4 \%)$ & I $(0.3 \%)$ & $2(0.5 \%)$ & 1.00 \\
\hline Tomatoes & $2(0.3 \%)$ & $2(0.6 \%)$ & $0(0 \%)$ & 0.22 \\
\hline Nuts & $3(0.4 \%)$ & I $(0.3 \%)$ & $2(0.5 \%)$ & 1.00 \\
\hline Banana & I (0.1\%) & $0(0 \%)$ & I $(0.3 \%)$ & 1.00 \\
\hline Sugarcane & I (0.1\%) & I $(0.3 \%)$ & $0(0 \%)$ & 0.47 \\
\hline Mango & 7 (1.0\%) & 4 (I.3\%) & $3(0.8 \%)$ & 0.71 \\
\hline
\end{tabular}

Note: $p$-value $<0.05$ was considered statistically significant (shown in bold). Abbreviations: TTH, tension-type headache; MSG, monosodium glutamate.

\section{Frequency of missing meals and dietary trigger factors in the Malay, Chinese and Indian patients with migraine and TTH}

Table 5 shows the frequency of missing meals and dietary triggers among the patients with migraine in the different ethnic groups. On univariate analysis, the Malays significantly had more dietary triggers for migraine compared to Indians $(p=0.004)$.

Table 6 illustrates the frequency of missing meals and dietary triggers among the patients with TTH in the various ethnic groups. On univariate analysis, the Malays significantly had more dietary triggers for TTH compared to Chinese $(p=0.016)$. The Malays significantly had more dietary triggers for TTH compared to Indians ( $p=0.011)$.

\section{Discussion}

Our study describes the dietary trigger factors and missing meals among the migraine and TTH patients in the three major ethnic groups in Malaysia. The present study showed that $23.1 \%$ of the study patients reported that missing meals triggered their headaches. This percentage was lower than the percentages described in other studies (39-82\%). ${ }^{22-24}$ Moreover, missing meals has been reported to precipitate migraine in $39-66 \%$ of the adult patients in previous

Table 4 Logistic regression of the various dietary triggers with TTH and migraine

\begin{tabular}{|c|c|c|c|c|c|}
\hline \multirow[t]{2}{*}{ Dietary triggers } & \multirow[t]{2}{*}{$p$-value } & \multicolumn{2}{|c|}{ Migraine } & \multicolumn{2}{|c|}{ TTH } \\
\hline & & OR & $95 \% \mathrm{Cl}$ & OR & $95 \% \mathrm{Cl}$ \\
\hline Chocolate & 0.035 & 2.16 & $1.06-4.4 \mathrm{I}$ & 0.46 & $0.23-0.95$ \\
\hline Coffee & 0.014 & 1.73 & I.12-2.68 & 0.58 & $0.37-0.89$ \\
\hline Food rich in MSG & 0.20 & 1.69 & $0.75-3.81$ & 0.59 & $0.26-1.33$ \\
\hline "Heaty” food & 0.97 & 1.03 & $0.22-4.93$ & 0.97 & $0.20-4.65$ \\
\hline Mutton & 0.84 & 0.91 & $0.37-2.25$ & $\mathrm{I} .14$ & $0.44-2.73$ \\
\hline Fatty meal & 0.72 & 0.83 & $0.30-2.32$ & 1.21 & $0.43-3.38$ \\
\hline Fried food & 0.36 & 0.62 & $0.22-1.75$ & 1.63 & $0.57-4.62$ \\
\hline Durian & 0.79 & 0.81 & $0.16-4.03$ & 1.24 & $0.25-6.19$ \\
\hline Tea & 0.62 & 1.26 & $0.50-3.21$ & 0.79 & $0.31-2.01$ \\
\hline Soft drinks & 0.053 & 3.20 & $0.98-10.40$ & 0.31 & $0.096-1.017$ \\
\hline Cheese & 0.47 & $|.5|$ & $0.49-4.64$ & 0.66 & $0.22-2.04$ \\
\hline Alcohol & 0.61 & 1.35 & $0.43-4.27$ & 0.74 & $0.23-2.35$ \\
\hline Spicy food & 0.65 & 1.52 & $0.25-9.40$ & 0.66 & $0.11-4.08$ \\
\hline Beef & 0.84 & 0.86 & $0.21-3.56$ & 1.16 & $0.28-4.76$ \\
\hline Oranges & 0.38 & 2.82 & $0.27-29.04$ & 0.35 & $0.034-3.65$ \\
\hline Instant noodles & 1.00 & NA & NA & NA & NA \\
\hline Onions & 0.29 & 4.64 & $0.27-80.70$ & 0.22 & $0.012-3.75$ \\
\hline Pineapples & 0.23 & 0.17 & $0.003-3.95$ & 8.58 & $0.25-291.36$ \\
\hline Lime & 0.70 & 0.52 & $0.019-14.19$ & 1.91 & $0.07-5 \mathrm{I} .77$ \\
\hline Egg & 0.47 & 0.39 & $0.044-5.72$ & 2.55 & $0.20-32.29$ \\
\hline Tomatoes & 1.00 & NA & NA & NA & NA \\
\hline Nuts & 0.58 & 0.50 & $0.04-5.72$ & 2.00 & $0.18-22.85$ \\
\hline Banana & 1.00 & NA & NA & NA & NA \\
\hline Sugarcane & 1.00 & NA & $\mathrm{NA}$ & NA & NA \\
\hline Mango & 0.92 & 1.12 & $0.12-10.76$ & 0.89 & $0.093-8.55$ \\
\hline
\end{tabular}

Note: $p$-values shown in bold are statistically significant.

Abbreviations: TTH, tension-type headache; MSG, monosodium glutamate; NA, not available. 
Table 5 Frequency of trigger factors in the Malay, Chinese and Indian patients with migraine

\begin{tabular}{|c|c|c|c|c|c|c|c|}
\hline \multirow[t]{2}{*}{$\begin{array}{l}\text { Trigger } \\
\text { factors }\end{array}$} & \multirow[t]{2}{*}{$\begin{array}{l}\text { Malays } \\
(n=159)\end{array}$} & \multirow[t]{2}{*}{$\begin{array}{l}\text { Chinese } \\
(n=67)\end{array}$} & \multirow[t]{2}{*}{$\begin{array}{l}\text { Indians } \\
(n=77)\end{array}$} & \multirow[t]{2}{*}{$\begin{array}{l}\text { Others } \\
(n=13)\end{array}$} & \multirow{2}{*}{$\begin{array}{l}\text { Malays vs } \\
\text { Chinese } \\
\text { p-value }\end{array}$} & \multirow{2}{*}{$\begin{array}{l}\text { Malays vs } \\
\text { Indians } \\
\text {-value }\end{array}$} & \multirow{2}{*}{$\begin{array}{l}\text { Chinese vs } \\
\text { Indians } \\
\text { p-value }\end{array}$} \\
\hline & & & & & & & \\
\hline Dietary & $84(52.8 \%)$ & 28 (4I.8\%) & 25 (32.5\%) & $5(38.5 \%)$ & 0.15 & 0.004 & 0.30 \\
\hline Missing meals & 59 (37.1\%) & 17 (25.4\%) & 20 (26.0\%) & I (7.7\%) & 0.093 & 0.11 & 1.00 \\
\hline
\end{tabular}

Note: $p$-value shown in bold is statistically significant.

Table 6 Frequency of dietary trigger and missing meals in the Malay, Chinese and Indian patients with TTH

\begin{tabular}{|c|c|c|c|c|c|c|c|}
\hline $\begin{array}{l}\text { Trigger } \\
\text { factors }\end{array}$ & $\begin{array}{l}\text { Malays } \\
(n=\mid 45)\end{array}$ & $\begin{array}{l}\text { Chinese } \\
(n=\mid 07)\end{array}$ & $\begin{array}{l}\text { Indians } \\
(n=92)\end{array}$ & $\begin{array}{l}\text { Others } \\
(n=24)\end{array}$ & $\begin{array}{l}\text { Malays } \\
\text { vs } \\
\text { Chinese }\end{array}$ & $\begin{array}{l}\text { Malays } \\
\text { vs } \\
\text { Indians }\end{array}$ & $\begin{array}{l}\text { Chinese } \\
\text { vs } \\
\text { Indians }\end{array}$ \\
\hline & & & & & $p$-value & $p$-value & p-value \\
\hline Dietary & 58 (40.0\%) & 27 (25.2\%) & 22 (23.9\%) & 7 (29.2\%) & 0.016 & 0.011 & 0.87 \\
\hline Missing meals & $3 \mathrm{I}(2 \mathrm{I} .4 \%)$ & $14(13.1 \%)$ & $12(13.0 \%)$ & $4(16.7 \%)$ & 0.098 & 0.12 & 1.00 \\
\hline
\end{tabular}

Note: $p$-values shown in bold are statistically significant. Abbreviation: TTH, tension-type headache.

studies..$^{9,10,12,13,15,17,23,25-28}$ In our study, a lower percentage of the patients with migraine reported that missing a meal was a trigger. Furthermore, the proportion of the TTH patients presenting with missing a meal was smaller compared to the migraine patients in our study, in agreement with a previous study. $^{8}$

The current study also demonstrated that $37.3 \%$ of the headache patients had dietary trigger factors. Dietary trigger factors are common trigger factors reported by patients with primary headache in the world..$^{8,25,29,30}$ The present study showed that $44.2 \%$ of the patients with migraine reported having dietary trigger, in concordance with previous studies. ${ }^{9,13-16,22,26,29}$ In previous studies, there were significant differences in dietary triggers demonstrated between migraine and TTH. ${ }^{31,32}$ Briefly, the percentages reported by the headache patients in previous studies varied depending on the patient cohort $(2.8-64 \%$ in migraine and $0-35 \%$ in TTH). ${ }^{8,9,13,15,22,26,29,31,32}$

Coffee was the most important dietary trigger factor of migraine and TTH in this study, in agreement with previous studies. ${ }^{6,12}$ Our study also demonstrated that coffee was the top precipitating factor in the migraine patients, consistent with other studies. ${ }^{13,14,29}$ We observed that more of our study migraine patients $(25.4 \%)$ reported that coffee was the trigger. This was higher than the percentages reported by AndressRothrock et al (14\%), Finocchi and Sivori (14\%) and Fukui et al $(8 \%) \cdot)^{9,13,15}$

Chocolate was the second most frequently implicated trigger factor among the migraine patients in this study, similar to a previous study. ${ }^{15}$ The percentage of $11.6 \%$ in these migraine patients was within the range reported in other studies (1.4-45\%)..$^{9,13,15,17,33}$
In previous studies, $29-36 \%$ of the migraine patients reported that alcohol provoked migraine episodes. ${ }^{16,17}$ However, in Malaysia, there is a lower alcohol consumption compared to other parts of the world. ${ }^{34}$ Moreover, the Malaysians consume less amount of cheese compared to the other regions in the world. This therefore explains that cheese was a trigger in only $3.8 \%$ of the migraine patients, a lower percentage than in previous studies. ${ }^{13,15,17}$

Ethnicity, culture and lifestyle changes play important roles in determining the triggers. ${ }^{6,10,22,25}$ Geographical factors also contribute to the differences in trigger factors. ${ }^{6,10,22,25}$ Certain foods such as mutton, spicy food and durians are more popular in South East Asia.

The appropriate and correct dietary counselling can be given by doctors and dietitians. The clinicians can advise a change of food consumption pattern and also consider alternative food choices. For example, the patients can be encouraged not to drink more than one cup of coffee per day. ${ }^{21}$ In addition, wine vinegar is an alternative to $\mathrm{MSG}^{21}$

The mechanisms for these ethnic differences remain poorly understood. One possible explanation is the influence of culture. However, we postulate that there are more reasons to explain the ethnic variation in dietary triggers besides the impact of culture. Therefore, more studies are needed in the future to examine the mechanisms and theories for ethnic variation in dietary factors.

In order to understand the differences of dietary triggers in the Malays, Chinese and Indians, the illness model and disease model may be applied. The relationship between diet and migraine is a composite function of changes in illness, disease and inflammation. ${ }^{11}$ The illness model examines the 
impact of food, diet and food culture on the biopsychosocial well-being of the migraine patients. ${ }^{11}$

The disease model encompasses clearly identifiable clinical and phenotypic characteristics as well as the availability of reliable biomarkers of diseases. ${ }^{11}$ Repeated exposures to food and inflammation and/or genetic predisposition trait may be present in these migraine patients. ${ }^{11}$ We postulate that we can also apply the two models to further elucidate the influence of culture and psychosocial factors together with genetic predisposition in the Malay, Chinese and Indian patients with regards to dietary triggers.

There is an increasing evidence that inflammation (immunoglobulin $\mathrm{G}$ [IgG], calcitonin gene related peptide, and nitric oxide) plays an important role in migraine..$^{35,36}$ Therefore, assessment of specific IgG to food is an ideal method to detect individually suspected food. ${ }^{35}$ This will enable a change of dietary habits so that chronic inflammation and onset of migraine in sensitized patients can be prevented. ${ }^{35}$ We therefore propose an individualized approach of the diet to relieve migraine. ${ }^{13,35,37} \mathrm{We}$ also suggest dietary restrictions based on the identification of food allergies by immunoglobulin E (IgE) and IgG antibodies. ${ }^{13}$

However, the associated decrease in quality of life needs to be taken into consideration, because strict food avoidance may result in stress, which in turn may eliminate a potentially beneficial effect. ${ }^{37}$ Doctors should carefully consider a balance between trigger avoidance and coping based on the individual patient. ${ }^{37}$ Generally, we feel that an anti-inflammatory diet as a health-promoting strategy should be proposed to be instituted for the patients. ${ }^{11,38}$

Missing a meal is a trigger for which avoidance is the best approach. ${ }^{8,12,37}$ Moreover, the patients will be encouraged to keep a food diary. ${ }^{33,37,38}$ The doctors will frequently encourage the headache patients to seek consistency in their lifestyle behaviors and dietary habits. ${ }^{11}$ Assessing the content of meals and the setting in which they are eaten will establish consistency, leading to lesser burden of disease in the migraine patients. ${ }^{11}$

Furthermore, eating behaviors can be further explored in the Malay, Chinese and Indian patients, because regulated eating habits may have the potential to decrease the occurrence of headache. ${ }^{24}$ The rituals associated with food may also play a role in the patient's experience of migraine. ${ }^{11}$ In addition to a cultural component, behavioral elements may predispose the patient to make conscious and subconscious choices of food. ${ }^{11}$ Future research studies can be conducted to determine whether the Malay patients have different neuroanatomic and neurochemical systems compared to the other ethnic groups. ${ }^{11}$
The strength of this study was the contribution of the study findings to the limited literature available on the dietary triggers in South East Asia. Moreover, the sample size was large and comprised of various Asian ethnic groups.

Evaluation of IgG to foods and drinks can be conducted in the Malay patients in the future. This will assist in improving the nutritional habits of the Malays in order to prevent or reduce migraine episodes. Diet restriction based on IgG antibodies may be a beneficial strategy in decreasing the frequency of migraine attacks and can be implemented for drug therapy-resistant patients. ${ }^{35}$

There were several limitations in this study. The study was clinic-based, and therefore selection bias could be present. Furthermore, this was a cross-sectional study, and the causeeffect could not be established. The presentation of the dietary triggers in a predetermined list could have introduced bias.

Other limitations were also present. The combination of foods, the latency between ingestion and headache attack, and the exact amount of food ingestion were not evaluated in this study. The exact amount of caffeine could vary among the different types of coffee drink, and according to different plant cultivar, maturation modalities, and roasting procedures.

In addition to the modality of coffee extraction which could modify the content of active principles, the presence of milk or other spices could also do the same to the drink. These concerns were also applicable to the other dietary triggers, such as chocolate. In the chocolate, the percentage of cocoa, presence of milk and/or nuts, fats other than cocoa butter, and the amount of sugars, should also be taken into account. The different commercial choices and traditional recipes could be confounding factors.

In conclusion, we observed that there were differences in certain dietary triggers among the various ethnic groups, in both migraine and TTH groups. More research is needed to improve our understanding of the dietary triggers of migraine and TTH, and optimize patient management. ${ }^{37}$ Future studies can be conducted to ascertain inflammationinduced migraine ( $\operatorname{IgE}$ and $\operatorname{IgG}$ ) in the Malay, Chinese and Indian patients. Moreover, more research studies can be conducted to determine the genetic traits in the different ethnic groups.

\section{Author contributions}

All authors contributed toward data analysis, drafting and critically revising the paper, gave final approval of the version published, and agree to be accountable for all aspects of the work. 


\section{Disclosure}

The authors report no conflicts of interest in this work.

\section{References}

1. Kim SK, Moon HS, Cha MJ, et al. Prevalence and features of a probable diagnosis in first-visit headache patients based on the criteria of the Third Beta Edition of the International Classification of Headache Disorders: A prospective, cross-sectional multicenter study. Headache. 2016;56(2):267-275.

2. Schuster NM, Rapoport AM. New strategies for the treatment and prevention of primary headache disorders. Nat Rev Neurol. 2016;12(11):635-650.

3. Alders EEA, Hentzen A, Tan CT. A community-based prevalence study on headache in Malaysia. Headache. 1996;36:379-384.

4. Schramm S, Uluduz D, Gouveia RG, et al. Headache service quality: evaluation of quality indicators in 14 specialist-care centres. $J$ Headache Pain. 2016;17(1):111.

5. Tai ML, Jivanadham JS, Tan CT, Sharma VK. Primary headache in the elderly in South-East Asia. J Headache Pain. 2012;13(4):291-297.

6. Wöber C, Holzhammer J, Zeitlhofer J, Wessely P, Wöber-Bingöl C. Trigger factors of migraine and tension-type headache: experience and knowledge of the patients. J Headache Pain. 2006;7(4):188-195.

7. Iliopoulos P, Damigos D, Kerezoudi E, et al. Trigger factors in primary headaches subtypes: a cross-sectional study from a tertiary centre in Greece. BMC Res Notes. 2015;8:393.

8. Wöber C, Wöber-Bingöl C. Triggers of migraine and tension-type headache. Handb Clin Neurol. 2010;97:161-172.

9. Andress-Rothrock D, King W, Rothrock J. An analysis of migraine triggers in a clinic-based population. Headache. 2010;50:1366-1370.

10. Zivadinov R, Willheim K, Sepic-Grahovac D, et al. Migraine and tension-type headache in Croatia: a population-based survey of precipitating factors. Cephalalgia. 2003;23(5):336-343.

11. Finkel AG, Yerry JA, Mann JD. Dietary considerations in migraine management: does a consistent diet improve migraine? Curr Pain Headache Rep. 2013;17(11):373.

12. Holzhammer J, Wöber C. [Alimentary trigger factors that provoke migraine and tension-type headache]. Schmerz. 2006;20(2):151-159. German.

13. Finocchi C, Sivori G. Food as trigger and aggravating factor of migraine. Neurol Sci. 2012;33(Suppl 1):S77-80

14. Savi L, Rainero I, Valfrè W, Gentile $\mathrm{S}$, Lo Giudice R, Pinessi L. Food and headache attacks. A comparison of patients with migraine and tension-type headache. Panminerva Med. 2002;44(1):27-31.

15. Fukui PT, Gonçalves TR, Strabelli CG, et al. Trigger factors in migraine patients. Arq Neuropsiquiatr. 2008;66(3A):494-499.

16. Martin VT, Vij B. Diet and Headache: Part 1. Headache. 2016;56(9): 1543-1552.

17. Peatfield RC. Relationships between food, wine, and beer-precipitated migrainous headaches. Headache. 1995;35(6):355-357.

18. International Headache Society. The International Classification of Headache Disorders; 2nd Edition. Available from: https://www.ichd-3. org/wp-content/uploads/2016/08/ihc_II_main_no_print.pdf. Accessed February 9, 2018.

19. Headache Classification Committee of International Headache Society (IHS). The International Classification of Headache Disorders 3rd ed. (beta version). Cephalalgia. 2013;33(9):629-808.

\section{Journal of Pain Research}

\section{Publish your work in this journal}

The Journal of Pain Research is an international, peer reviewed, open access, online journal that welcomes laboratory and clinical findings in the fields of pain research and the prevention and management of pain. Original research, reviews, symposium reports, hypothesis formation and commentaries are all considered for publication.
20. Lu SR, Fuh JL, Chen WT, Juang KD, Wang SJ. Chronic daily headache in Taipei, Taiwan: prevalence, follow-up and outcome predictors. Cephalalgia. 2001;21:980-986.

21. Zencirci B. Comparison of the effects of dietary factors in the management and prophylaxis of migraine. J Pain Res. 2010;3:125-130.

22. Carod-Artal FJ, Ezpeleta D, Martín-Barriga ML, Guerrero AL. Triggers, symptoms, and treatment in two populations of migraneurs in Brazil and Spain. A cross-cultural study. J Neurol Sci. 2011;304(1-2):25-28.

23. Diamond S, Prager J, Freitag FG. Diet and headache. Is there a link? Postgrad Med. 1986;79(4):279-286.

24. Turner DP, Smitherman TA, Penzien DB, Porter JA, Martin VT, Houle TT. Nighttime snacking, stress, and migraine activity. J Clin Neurosci. 2014;21(4):638-643.

25. Wang J, Huang Q, Li N, Tan G, Chen L, Zhou J. Triggers of migraine and tension-type headache in China: a clinic-based survey. Eur J Neurol. 2013;20(4):689-696.

26. Kelman L. The triggers or precipitants of the acute migraine attack. Cephalalgia. 2007;27(5):394-402.

27. Spierings ELH, Ranke AH, Honkoop PC. Precipitating and aggravating factors of migraine versus tension type headache. Headache. 2001;41:554-558.

28. Martin PR, Seneviratne HM. Effects of food deprivation and a stressor on head pain. Health Psychol. 1997;16:310-318.

29. Zaeem Z, Zhou L, Dilli E. Headaches: A review of the role of dietary factors. Curr Neurol Neurosci Rep. 2016;16(11):101.

30. Karli N, Zarifoglu M, Calisir N, Akgoz S. Comparison of pre-headache phases and trigger factors of migraine and episodic tension-type headache: do they share similar clinical pathophysiology? Cephalalgia. 2005;25(6):444-451.

31. Haque B, Rahman KM, Hoque A, et al. Precipitating and relieving factors of migraine versus tension type headache. BMC Neurol. 2012;12:82.

32. Chabriat H, Danchot J, Michel P, Joire JE, Henry P. Precipitating factors of headache. A prospective study in a national control-matched survey in migraineurs and nonmigraineurs. Headache. 1999;39(5): 335-338.

33. Bánk J, Márton S. Hungarian migraine epidemiology. Headache. 2000;40:164-169.

34. Kamarudin RB; Disease Control Division, Ministry of Health, Malaysia. Alcohol consumption in Malaysia; NHMS 2011 data. Presentation at 15th National Institutes of Health (NIH) Scientific Meeting 2012. Available from: http://www.ihm.moh.gov.my/images/files/15th-NIHScientific-Meeting/NIHSM-2012-LecNotes/SP6-ALCOHOL\%20 CONSUMPTION\%20IN\%20MALAYSIA-Dr\%20Rozanim.pdf. Accessed August 17, 2017.

35. Alpay K, Ertas M, Orhan EK, Ustay DK, Lieners C, Baykan B. Diet restriction in migraine, based on IgG against foods: a clinical doubleblind, randomised, cross-over trial. Cephalalgia. 2010;30(7):829-837.

36. Geppetti P, Capone JG, Trevisani M, Nicoletti P, Zagli G, Tola MR. CGRP and migraine; neurogenic inflammation revisited. J Headache Pain. 2005;6:61-70.

37. Hoffmann J, Recober A. Migraine and triggers: post hoc ergo propter hoc? Curr Pain Headache Rep. 2013;17(10):370.

38. Ramsden CE, Ringel A, Feldstein AE, et al. Lowering dietary linoleic acid reduces bioactive oxidized linoleic acid metabolites in humans. Prostaglandins Leukot Essent Fatty Acids. 2012;87:135-141.

The manuscript management system is completely online and includes a very quick and fair peer-review system, which is all easy to use. Visit http://www.dovepress.com/testimonials.php to read real quotes from published authors. 